\title{
Effect of Self-myofascial Release on Reduction of Physical Stress: A Pilot Study
}

\author{
Kanghoon Kim, MS, $\mathrm{PT}^{1)}$, Sunghyun Park, BSc, $\mathrm{PT}^{1)^{*}}$, Bong-Oh Goo, PhD, $\mathrm{PT}^{1)}$, \\ Seok-Cheol Chol, $\mathrm{PhD}^{2}$ ) \\ 1) Department of Physical Therapy, College of Health Sciences, Catholic University of Pusan: 9 Bugok \\ 3-dong, Geumjung-gu, Busan 609-757 Republic of Korea \\ 2) Department of Clinical Laboratory Science, College of Health Sciences, Catholic University of \\ Pusan, Republic of Korea
}

\begin{abstract}
Purpose] This study aims to examined the effect of the self-myofascial release induced with a foam roller on the reduction of stress by measuring the serum concentration of cortisol. [Subjects and Methods] The subjects of this study were healthy females in their 20s. They were divided into the experimental and control groups. Both groups, each consisting of 12 subjects, were directed to walk for 30 minutes on a treadmill. The control group rested for 30 minutes of rest by lying down, whereas the experimental group was performed a 30 minutes of selfmyofascial release program. [Results] Statistically significant levels of cortisol concentration reduction were observed in both the experimental group, which used the foam roller, and the control group. There was no statistically significant difference between the two groups. [Conclusion] The Self-myofascial release induced with a foam roller did not affect the reduction of stress.

Key words: Myofascial release, Cortisol, Foam roller
\end{abstract}

(This article was submitted Apr. 18, 2014, and was accepted May 16, 2014)

\section{INTRODUCTION}

The human body has a mechanism of maintaining internal homeostasis against external changes. However, stress threatens the mechanism for the maintenance of homeostasis $^{1,2)}$. Stress is a non-specific biological reaction, which occurs in response to physical injuries and stimulations imparted to the body, and it modifies the immune system.

Stress is determined by mental and physical factors. In particular, physical stress excites exacerbation of the sympathetic nervous system and increase heartbeat, and imparts negatively influences on the immune system to a greater extent than mental stress ${ }^{3)}$. In addition, physical stress induces muscular modification or repetitive strain injuries, causing muscular imbalance and inflammation ${ }^{4}$. Inflammation in turn becomes a cause of increased muscular tension and spasms ${ }^{5)}$. Muscular tension can promote formation of taut bands or trigger points in the myofascia, which can develop into myofascial pain syndrome ${ }^{6}$. Myofascial pain syndrome creates a vicious cycle of "pain - spasm - pain." If this vicious cycle is not interrupted at an early stage, it will inevitably become a chronic problem. This vicious cycle of pain leads to psychological stress, which becomes the cause

*Corresponding author. Sunghyun Park (E-mail: nongkuman@hanmail.net)

(C2014 The Society of Physical Therapy Science. Published by IPEC Inc. This is an open-access article distributed under the terms of the Creative Commons Attribution Non-Commercial No Derivatives (by-ncnd) License $<$ http://creativecommons.org/licenses/by-nc-nd/3.0/> . of continuous pain ${ }^{6}$.

There are a wide range of physiotherapy interventions for physical stress, and, in particular, myofascial release is an excellent method that can mitigate the damage caused by physical stress with low-load mechanical stimulation ${ }^{7)}$. Myofascial release is a method of stretching the myofascial system with low load over a prolonged period of time in order to enhance the functions of the human body, reduce pain and secure appropriate muscle length ${ }^{8}$. Myofascial release performed by a therapist induces recovery in the damaged area of the muscle and reduces inflammation and edema $^{9,10)}$. However, it is difficult to perform this therapy alone.

Recently, a method using a foam roller to induce selfmyofascial release has been introduced ${ }^{11)}$. Preceding studies conducted on self-myofascial release using a foam roller have mainly focused on the range of joint movement and changes in posture with the findings evaluated from a biomechanical perspective ${ }^{11)}$. However, it has been asserted that the reliability of the biomechanical measurement is low and the biological results of mechanical stimulation must be considered ${ }^{12)}$. Accordingly, this study measured the serum concentration of cortisol, a biological factor, to determine whether the mechanical stimulation provided by a foam roller is effective at reducing stress.

\section{SUBJECTS AND METHODS}

Twenty-four healthy females in their 20s were selected as the subjects of this study. The subjects were randomly and evenly assigned to an experimental group and a control 
group. All the subjects were directed to walk on a treadmill for 30 minutes at the normal walking speed of $1.2 \mathrm{~m} / \mathrm{s}$, while wearing high-heeled shoes in order to induce physical stress. ${ }^{13)}$ Sufficient explanation of the experimental procedure and the purpose of the study was provided to the subjects who signed consent forms prior to their participation. Then, approval form the Ethics Committee of the Catholic University of Pusan was acquired (CUPIRB-2013-019).

After the subjects had walked on the treadmill for 30 minutes, 12 subjects of the experimental group performed the 30-min myofascial release technique using a foam roller, while the 12 control group subjects were instructed to rest comfortably on their backs for 30 minutes. During the 30-minute self-myofascial release program, pressure was applied on a single spot for 30 seconds using the subject's body weight in order to stimulate the corresponding muscle over a period of 3 to 6 minutes as a means of alleviating muscle tension in the spine and areas around the 4 limbs. The program was performed as follows:

Myofascial release of the entire spine, 6 minutes; of the cervix, 6 minutes; of the thorax, 6 minutes; of the quadriceps femoris muscle, 3 minutes; of the hamstring, 3 minutes; of the tensor fascia latae, 3 minutes; and of the calf muscle, 3 minutes.

Blood $(10 \mathrm{ml})$ was collected from the vein in the forearm of the subjects after they had completed the walking exercise on the treadmill, and after 30 minutes of myofascial release with the foam roller (the experimental group) or after 30 minutes of rest (the control group). All the subjects were instructed to arrive at the laboratory with empty stomach on the day of the experiment, by fasting from 9 p.m. on the previous day, and they rested for 30 minutes upon arrival at the laboratory. The blood samples were immediately placed in heparinized tubes and centrifuged for over 15 minutes at the speed of $300 \mathrm{rpm}$. The serum was separated and stored at a temperature below $-70{ }^{\circ} \mathrm{C}$. Analysis was performed by the Clinical Pathology Department of the Catholic University of Busan.

Data were processed using the statistical program SPSS 19.0. For all the measured data, the mean and standard deviation values were computed for each of the variables. In order to investigate the effect of the self-myofascial release method using a foam roller on physical stress, the paired ttest was performed. The independent t-test was performed to verify the differences between the groups. The statistical significance level was chosen as $\alpha=0.05$.

\section{RESULTS}

The general characteristics of the subjects of this study are summarized in Table 1. The concentrations of cortisol of the experimental group and the control group are summarized in Table 2. The concentration of cortisol of the experimental group following the use of the foam roller showed a statistically significant decrease $(p<0.05)$. The concentration of cortisol of the control group following rest also showed a statistically significant decrease $(p<0.05)$. There was no significant difference between the two groups $(\mathrm{p}>0.05)$.
Table 1. General characteristics of the participants

\begin{tabular}{lcc}
\hline & $\begin{array}{c}\text { Experimental group } \\
(\mathrm{n}=12)\end{array}$ & $\begin{array}{c}\text { Control group } \\
(\mathrm{n}=12)\end{array}$ \\
\hline Age $(\mathrm{y})$ & $22.8 \pm 1.7$ & $22.5 \pm 1.8$ \\
Weight $(\mathrm{kg})$ & $51.5 \pm 1.5$ & $50.7 \pm 1.7$ \\
Height $(\mathrm{cm})$ & $157.3 \pm 3.6$ & $158.5 \pm 2.7$ \\
\hline
\end{tabular}

Table 2. The comparison of Cortisol levels (ng/ml)

\begin{tabular}{lcc}
\hline & Experimental group & Control group \\
\hline Pre & $28.6 \pm 1.3$ & $28.0 \pm 1.7$ \\
Post & $24.5 \pm 3.2^{*}$ & $25.1 \pm 2.4^{*}$ \\
\hline
\end{tabular}

*Statistically significant difference between pre-test and post-test $(\mathrm{p}<0.05)$.

\section{DISCUSSION}

This study was conducted to examine the effect of a self myofascial release technique using a foam roller on physical stress.

Several studies have evaluated stress by analyzing catecholamine and cortisol ${ }^{14,15)}$. Catecholamines, which include norepinephrine and epinephrine, excite the sympathetic nervous system. However, they have a very short half-life of 1 to 2 minutes, making their evaluation very difficult ${ }^{16)}$. In contrast, cortisol, which is necessary for the excitation of the sympathetic nervous system by catecholamines, has a half-life of approximately 20 to 40 minutes; thus, it can be a reliable index of stress ${ }^{17)}$. In addition, it can be used to indirectly predict the activities of the sympathetic nerves. Therefore, the concentration of cortisol hormone was measured as the index of stress in this study.

In this study, the blood cortisol levels of both the experimental and control groups showed significant reductions 30 min after the completion of treadmill walking. However, there was no statistically significant difference between the two groups. This can be explained as follows. First, cortisol, which is a key adrenocortical hormone, has a daily rhythm. Thus, the cortisol level normally changes throughout the day, with the highest levels being in the morning and the lowest levels in the evening ${ }^{17)}$. For more accurate measurement of the cortisol level, it should be measured twice, at about 8:30 a.m and 4 p.m., the approximate times of maximum and minimum cortisol secretion. However, in this study, blood was collected only at about 8:30 a.m. when the cortisol secretion is highest, and this may have masked differences between the 2 groups. Second, the subjects of the control group were instructed to lie down during rest, and this posture increases cerebral blood flow ${ }^{18)}$. An increase in blood flow is known to play a role in reducing stress $^{18)}$. Therefore, it is possible that this resulted in levels of cortisol in the control group being similar to those of the experimental group.

The blood cortisol level of the experimental group after the application of the foam roller was lower than that of the control group, but the difference was not significant. We think that the self-myofascial release technique affected the 
autonomic nervous system of the subjects in the experimental group. Schleip asserted that there are "smooth muscle cells" in the myofascia that contract in addition to becoming tensed ${ }^{19)}$. These cells are capable of controlling the autonomic nervous system independent of muscular tension. The self-myofascial release technique used in this study applies very slow, gradual and deep pressure which we think lowers the activities of the sympathetic nerves. This effect is achieved by promoting the interstitial receptor effects that control the autonomic nerves through the stimulation of Ruffini endings ${ }^{19}$. In other words, we consider the selfmyofascial release technique increased the activation of the parasympathetic nerves, thereby reducing stress.

In this study, application of the self-myofascial release technique using a foam roller after exposure to physical stress resulted in better effects on stress reduction, on average, than taking a rest, even though there was no significant difference. We consider it necessary to repeat the experiment with a larger number of subjects in the future.

\section{REFERENCES}

Cannon WB: Bodily changes in pain, hunger, fear and rage. 1929

Selye H: The stress of life 1956

3) Landmann RM, Müller FB, Perini C, et al.: Changes of immunoregulatory cells induced by psychological and physical stress: relationship to plasma catecholamines. Clin Exp Immunol, 1984, 58: 127-135. [Medline]

4) Gray JM, Alpar EK: Peroneal tenosynovitis following ankle sprains. Injury, 2001, 32: 487-489. [Medline] [CrossRef]

5) Chaitow L: Palpation Skills. Churchill Livingstone, 1997.

6) Simons DG, Travell JG, Simons LS: Travell \& Simons' Myofascial Pain and Dysfunction: Upper Half of Body. Lippincott Williams \& Wilkins, 1999.

7) Tozzi P, Bongiorno D, Vitturini C: Fascial release effects on patients with non-specific cervical or lumbar pain. J Bodyw Mov Ther, 2011, 15: 405416. [Medline] [CrossRef]

8) Barnes JF: Myofascial Release: The Search for Excellence: A Comprehensive Evaluatory and Treatment Approach: JF Barnes, 1990.

9) Kuruma H, Takei $\mathrm{H}$, Nitta $\mathrm{O}$, et al.: Effects of myofascial release and stretching technique on range of motion and reaction time. J Phys Ther Sci, 2013, 25: 169-171. [CrossRef]

10) Grod JP: Myofascial manipulation: theory and clinical application. J Can Chiropr Assoc, 1994, 38: 181.

11) MacDonald GZ, Penney MD, Mullaley ME, et al.: An acute bout of selfmyofascial release increases range of motion without a subsequent decrease in muscle activation or force. J Strength Cond Res, 2013, 27: 812821. [Medline] [CrossRef]

12) Bialosky JE, Bishop MD, Price DD, et al.: The mechanisms of manual therapy in the treatment of musculoskeletal pain: a comprehensive model. Man Ther, 2009, 14: 531-538. [Medline] [CrossRef]

13) Lafortune MA, Cavanagh PR, Sommer HJ 3rd, et al.: Three-dimensional kinematics of the human knee during walking. J Biomech, 1992, 25: $347-$ 357. [Medline] [CrossRef]

14) Acolet $D$, Modi N, Giannakoulopoulos $X$, et al.: Changes in plasma cortisol and catecholamine concentrations in response to massage in preterm infants. Arch Dis Child, 1993, 68: 29-31. [Medline] [CrossRef]

15) Field T, Grizzle N, Scafidi F, et al.: Massage theraphy for infants of depressed mothers. Infant Behav Dev, 1996, 19: 107-112. [CrossRef]

16) Peaston RT, Weinkove C: Measurement of catecholamines and their metabolites. Ann Clin Biochem, 2004, 41: 17-38. [Medline] [CrossRef]

17) Nicolson NA: Measurement of Cortisol. Handbook of Physiological Research Methods in Health Psychology, 2008, pp 37-74.

18) Ouchi $Y$, Kanno T, Okada H, et al.: Changes in cerebral blood flow under the prone condition with and without massage. Neurosci Lett, 2006, 407: 131-135. [Medline] [CrossRef]

19) Schleip R: Fascial plasticity — a new neurobiological explanation: Part 1. J Bodyw Mov Ther, 2003, 7: 11-19. [CrossRef] 